\title{
Environmental risk assessment of chemicals and nanomaterials - The best foundation for regulatory decision-making?
}

Syberg, Kristian; Hansen, Steffen Foss

\section{Published in:}

Science of the Total Environment

Link to article, DOI:

10.1016/j.scitotenv.2015.09.112

Publication date:

2016

Document Version

Peer reviewed version

Link back to DTU Orbit

Citation (APA):

Syberg, K., \& Hansen, S. F. (2016). Environmental risk assessment of chemicals and nanomaterials - The best foundation for regulatory decision-making? Science of the Total Environment, 541, 784-794.

https://doi.org/10.1016/j.scitotenv.2015.09.112

\section{General rights}

Copyright and moral rights for the publications made accessible in the public portal are retained by the authors and/or other copyright owners and it is a condition of accessing publications that users recognise and abide by the legal requirements associated with these rights.

- Users may download and print one copy of any publication from the public portal for the purpose of private study or research.

- You may not further distribute the material or use it for any profit-making activity or commercial gain

- You may freely distribute the URL identifying the publication in the public portal 
This is a post-print version of Syberg, K., \& Hansen, S. F. (2016). Environmental risk assessment of chemicals and nanomaterials - The best foundation for regulatory decision-making? Science of the Total Environment, 541, 784-794. The printed version of the paper is available at: DOI: 10.1016/j.scitotenv.2015.09.112

1 Environmental Risk Assessment of Chemicals and Nanomaterials 2 The Best Foundation for Regulatory Decision-Making?

$4 \quad$ Kristian Syberg*a, Steffen Foss Hansen

5 a Department of Environmental, Social and Spatial Change, Roskilde University, Denmark

6 b DTU Environment, Department of Environmental Engineering, Technical University of Denmark

$7 \quad$ * Corresponding author: ksyberg@ruc.dk 
This is a post-print version of Syberg, K., \& Hansen, S. F. (2016). Environmental risk assessment of chemicals and nanomaterials - The best foundation for regulatory decision-making? Science of the Total Environment, 541, 784-794. The printed version of the paper is available at: DOI: 10.1016/j.scitotenv.2015.09.112

\section{Abstract}

3

Environmental risk assessment (ERA) is often considered as the most transparent, objective and reliable

decision-making tool for informing the risk management of chemicals and nanomaterials. ERAs are based on the assumption that it is possible to provide accurate estimates of hazard and exposure and, subsequently, to quantify risk. In this paper we argue that since the quantification of risk is dominated by uncertainties, ERAs do not provide a transparent or an objective foundation for decision-making and they should therefore not be considered as a "holy grail" for informing risk management. We build this thesis on the analysis of two case studies (of nonylphenol and nanomaterials) as well as a historical analysis in which we address the scientific foundation for ERAs. The analyses show that ERAs do not properly address all aspects of actual risk, such as the mixture effect and the environmentally realistic risk from nanomaterials. Uncertainties have been recognised for decades, and assessment factors are used to compensate for the lack of realism in ERAs. The assessment factors' values were pragmatically determined, thus lowering the scientific accuracy of the ERAs. Furthermore, the default choice of standard assay for assessing a hazard might not always be the most biologically relevant, so we therefore argue that an ERA should be viewed as a pragmatic decision-making tool among several, and it should not have a special status for informing risk management. In relation to other relevant decision-making tools we discuss the use of chemical alternative assessments (CAAs) and the precautionary principle.

\section{Keywords}

Environmental risk assessment, assessment factors, nonylphenol, nanomaterials, REACH, chemical regulation 
This is a post-print version of Syberg, K., \& Hansen, S. F. (2016). Environmental risk assessment of chemicals and nanomaterials - The best foundation for regulatory decision-making? Science of the Total Environment, 541, 784-794. The printed version of the paper is available at: DOI: 10.1016/j.scitotenv.2015.09.112

\section{Highlights}

- Environmental risk assessments (ERAs) are the preferred choice for informing chemical risk management.

- Two case studies and a historical analysis show that ERAs are not as scientifically well-founded as often perceived.

- ERAs are a pragmatic decision-making tool and should be applied as such, rather than being afforded special status. 
This is a post-print version of Syberg, K., \& Hansen, S. F. (2016). Environmental risk assessment of chemicals and nanomaterials - The best foundation for regulatory decision-making? Science of the Total Environment, 541, 784-794. The printed version of the paper is available at: DOI: 10.1016/j.scitotenv.2015.09.112

\section{1. Introduction}

An environmental risk assessment (ERA) is often championed as the preferred decision-making framework for regulators looking to ensure that the regulation and risk management of chemicals and nanomaterials are enforced in the most transparent, objective and reliable way for society (van Leeuwen and Vermeire 1995). An ERA, in many aspects, is regarded as the "holy grail” for addressing risk, one of the major reasons for which is that it is considered the best approach to ensure scientific and evidence-based regulation (Löfsted 2011). In a world where risk perception is believed to be a strong driver of risk management (Slovic 1999), some argue that it is increasingly more important that policymaking is driven by evidence rather than political dogma (Holmes and Clark 2008). ERAAs are considered to be a cornerstone in regard to ensuring such evidence-based foundations for regulation, and they now provide the backbone of many pieces of European legislation, such as the water framework directive, biocidal product legislation and chemical legislation known as REACH (EC 2000, 2006 2012).

The fundamental hypothesis on which the ERA paradigm is based is that risk is a function of hazard and exposure. When an ERA is conducted, the hazard and concentration-response assessments, based on the principle that toxicity is concentration-dependent, form the foundation for determining a toxicity threshold. This assessed potency is thereupon used to assess risk by comparing the derived threshold for toxicity with exposure concentrations (EC 2003). This implies that accurate measurements of the hazard and concentration response relationship can be provided, where uncertainties ideally should be negligible or at least well-quantifiable. These experimentally derived assessments thus form the very foundation of ERAs and thereby the "evidence-based" foundations with which they are supposed to provide decision-makers. The four steps of risk assessment (i.e. hazard identification, dose-response assessment, exposure assessment and risk characterisation) were originally proposed by the US National Research Council of the National Academy of Sciences (NRC-NAS) in their landmark 1983 publication “The Red Book” (NRC 1983). During the 1990s, the US EPA adapted the RA framework to ecological risk assessment for assessing risk where human health is not the primary focus. For instance, in 1992, the US EPA published the report Framework 
This is a post-print version of Syberg, K., \& Hansen, S. F. (2016). Environmental risk assessment of chemicals and nanomaterials - The best foundation for regulatory decision-making? Science of the Total Environment, 541, 784-794. The printed version of the paper is available at: DOI: 10.1016/j.scitotenv.2015.09.112

for Ecological Risk Assessment, which proposed principles and terminology for this process (US EPA 1992), which was summarily adopted in the EU via the Technical Guidance Documents (TGDs), although no references are provided within these guidelines (EC 1993a). While its intentions have always been good, the ERA framework has increasingly come under critical scrutiny and has been criticised for not being able to provide the input that risk managers need, and so modifications are currently being discussed in the EU (Scientific Committees 2013).

One of the key limitations of the ERA seems to be that risks can only first be truly assessed after an adverse impact has been firmly established scientifically, which is unfortunate when it comes to protecting the environment (EEA 2001, 2013). Article 191 of the Lisbon Treaty states that the protection of the environment 'shall be based on the precautionary principle and on the principles that preventive action should be taken' (EU 2007). An important question is therefore whether an ERA can provide sufficient knowledge for decision-makers to, on the one hand, ensure "evidence-based" regulation and on the other hand provide them with enough decision-making support in time to take precautionary preventive actions. In this paper, we argue that the answer to this question is "no." In order to explain our conclusion, we first analyse how the first two steps of the ERA framework, namely hazard identification and dose-response assessment, are used to inform decision-making in two specific cases. We do this in order to illustrate some of the challenges that ERAs face when it comes to assessing the hazardous nature of chemicals and nanomaterials. The first case considers one of the most comprehensive environmental risk assessments ever performed in the EU, namely in respect to nonylphenol, while the second case examines engineered nanomaterials (ENMs).

Based on the nature of the identified challenges, we would argue that they cannot be addressed solely by revising ERAs in the future; rather, they are a reflection of the fundamental limitations of the ERA framework. Via a historical analysis of the development of ERAs, we discuss how these limitations, related to hazard identification and dose-response assessment identified in the two cases, have been well-recognised over time but unfortunately never really addressed. Finally, we discuss how 
This is a post-print version of Syberg, K., \& Hansen, S. F. (2016). Environmental risk assessment of chemicals and nanomaterials - The best foundation for regulatory decision-making? Science of the Total Environment, 541, 784-794. The printed version of the paper is available at: DOI: 10.1016/j.scitotenv.2015.09.112

alternatives such as the precautionary principle and alternative assessment may help to ensure a more timely and transparent foundation for policymaking. First, however, we provide a short introduction to the principles of environmental risk assessment in the EU.

\section{Environmental risk assessment in Europe}

\subsection{Laying down the principles of risk assessment in the EU}

Directive 93/67/EEC describes how a risk assessment entails hazard identification, dose (concentration)response (effect) assessment, exposure assessment for environmental compartments (i.e. aquatic environment, terrestrial environment and air) and risk characterisation (EC 1993b). The objective of the dose (concentration)-response (effect) assessment is to 'predict the concentration of the substance below which adverse effects in the environmental compartment of concern are not expected to occur'. This concentration is known as the "predicted no-effect concentration" (PNEC) and has to be determined on the basis of information in the notification dossier, e.g. a 21-day study on daphnia magna, testing of higher plant orders and earthworms. A PNEC has to be derived by applying an assessment factor to the values resulting from tests on organisms, e.g. LC50 (median lethal concentration), EC50 (median effective concentration) and NOEL(C) (no-observed-effect level (concentration)) (Table 1). These assessment factors (AFs) are seen as '[...] an expression of the degree of uncertainty in extrapolation from test data on a limited number of species to the real environment', and an AF of the order of 1000 is typically applied to an L(E)C50 value derived from the results of testing for acute toxicity, though it may be reduced in the light of other relevant information. A lower AF is typically applied to a NOEC derived from the results of testing for chronic toxicity, and the AF can be lowered further in cases where more comprehensive data, such as species sensitivity distributions, are available.

Table 1. Assessment factors for deriving a $\mathrm{PNEC}_{\text {aquatic }}{ }^{*}$, recommended in Table 16 of the 2003 Technical Guidance document (EC 2003). 
This is a post-print version of Syberg, K., \& Hansen, S. F. (2016). Environmental risk assessment of chemicals and nanomaterials - The best foundation for regulatory decision-making? Science of the Total Environment, 541, 784-794. The printed version of the paper is available at: DOI: 10.1016/j.scitotenv.2015.09.112

\begin{tabular}{|l|c|}
\hline $\begin{array}{l}\text { At least one short-term L(E)C50** from each of the three } \\
\text { trophic levels of the base set (fish, daphnia and algae) }\end{array}$ & 1000 \\
\hline One long-term NOEC & 100 \\
\hline $\begin{array}{l}\text { Two long-term NOECs from species representing two } \\
\text { trophic levels (fish and/or daphnia and/or algae) }\end{array}$ & 50 \\
\hline $\begin{array}{l}\text { Long-term NOECs from at least three species (normally } \\
\text { fish, daphnia and algae) representing three trophic levels }\end{array}$ & 10 \\
\hline Species sensitivity distribution (SSD) method & $\begin{array}{c}5-1 \\
\text { (To be fully justified case by case) }\end{array}$ \\
\hline Field data or model ecosystem & Reviewed on a case by case basis \\
\hline
\end{tabular}

** L(E)C50 : lethal(effect) concentration for $50 \%$ of the test specimens

*** NOEC: no observed effect concentration

The final step in the risk assessment methodology entails comparing the predicted exposure concentration

(PEC) with the PNEC for any given compartment, so that a PEC/PNEC ratio may be derived. If the

PEC/PNEC ratio is $\leq 1$, it implies that there is no immediate concern according to the available information.

8 If the ratio is $\geq 1$, the competent authority shall judge whether: 1 ) the substance is of concern and further

information is required for the revision of the assessment, but it shall defer a request for that information

until the next tonnage threshold is reached, 2) the substance is of concern and further information shall be

requested immediately or 3) the substance is of concern and the competent authority shall immediately make

recommendations for risk reduction. The type and amount of data required for the ERA is based on the

production volume of the chemical, because with a greater production volume comes a greater demand for

experimental data. The tonnage threshold thus refers to a production volume where the required set of data is

expanded to include additional data. If it has not been possible to derive a PEC/PNEC ratio, the risk

characterisation shall entail a qualitative evaluation of the likelihood that an effect will occur under the

expected conditions of exposure.

\subsection{The emergence of the Technical Guidance Documents}

Although Directive 93/67, Regulation 1488/94 and Directive 98/8 lay down general principles for the risk assessment of new substances, existing substances and biocidally active substances or substances of concern present in a biocidal product, they do not include extensive technical details for conducting such risk 
This is a post-print version of Syberg, K., \& Hansen, S. F. (2016). Environmental risk assessment of chemicals and nanomaterials - The best foundation for regulatory decision-making? Science of the Total Environment, 541, 784-794. The printed version of the paper is available at: DOI: 10.1016/j.scitotenv.2015.09.112

first set of “Technical Guidance Documents on Risk Assessment” (EC 1993a, 1994), which were prepared in order to support Commission Directive 93/67/EEC on Risk Assessment for newly notified substances, Commission Regulation (EC) No 1488/94 on Risk Assessment for existing substances and Directive 98/8/EC of the European Parliament and of the Council concerning the placing of biocidal products on the market. Key aspects of the risk assessment methodology, such as PEC/PNEC-derivation, the use of assessment factors (Table 1) and the four steps of risk assessment, were described in these first TGD versions. Regrettably these TGDs provide no discussion on the uncertainties or the scientific foundations of these significant methodological choices, and it is unclear on which kinds of evidence and insight these are based. In 2003, the TGDs were updated with respect to ERAs, and the effect assessment took on major improvements (e.g. a new chapter on marine risk assessment was added). In 2007, a new regulation for industrial chemicals, called REACH (short for: Registration, Evaluation, Assessment and Restriction of Chemicals), was adopted (EC 2006). Under REACH, manufacturers and importers of chemical substances are required to carry out chemical safety assessments (CSAs) when producing or importing chemicals in quantities of 10 tonnes or more per year. The European Chemical Agency has provided substantial guidance on how it would like industry to prepare these CSAs, and although the terminology is different, the key aspects of the CSA are similar to the chemical risk assessment methodology described in the TDG prepared by the ECB (ECHA 2008).

The (largely) experimentally derived PNECs thus form the foundation of the "evidencebased" input into the decision-making process in Europe, in both a historical and a future context. It is therefore interesting to analyse the nature of the science that is being applied within ERAs aiming at deriving PNECs. 
This is a post-print version of Syberg, K., \& Hansen, S. F. (2016). Environmental risk assessment of chemicals and nanomaterials - The best foundation for regulatory decision-making? Science of the Total Environment, 541, 784-794. The printed version of the paper is available at: DOI: 10.1016/j.scitotenv.2015.09.112

\section{Hazard and dose-response assessment of nonylphenol}

Nonylphenol is an industrial chemical mainly used in nonylphenol ethoxylates production (NPEO) (85\% of total production) (Nielsen et al. 2000), which in turn is used as a detergent for industrial cleaning, as a stabiliser in plastics such as PVC and NPEO and in paint formulations (ECHA 2014). In 1997, nonylphenol had a yearly production volume of 73,500 tonnes (EC 2002), making it a high-volume production chemical at the time. It was chosen as one of the substances to be risk assessed under the old European Regulation 793/93 (EC 2002), due to its high production volume and toxic properties. The final risk assessment was published in 2002, building on a review of the scientific data completed in 1999. The RA provides a 'comprehensive risk assessment of 4-nonylphenol (branced) and nonylphenol' (EC 2002), and so it is therefore well-suited to illustrating some of the challenges in environmental risk assessments, even for ERAs that were considered and portrayed as scientifically "state-of-the-art” at the time.

\subsection{Hazard identification of nonylphenol}

ERA hazard identification was based on a review of studies conducted by the EU rapporteur (UK authorities). The report concludes that endpoints such as growth and survival were the most sensitive, and these endpoints are therefore used for assessing PNECs (Table 2) (EC 2002).

\subsubsection{Endocrine disrupting effects and "new" versus traditional endpoints}

Even though the reported endocrine disrupting effects of nonylphenol are discussed in the ERA report, it is concluded that their threshold values are higher than those for more "traditional" endpoints (EC 2002). The ERA arrives at this conclusion because oestrogenic effects started around 10-20 $\mu \mathrm{g} / \mathrm{l}$ whereas the PNEC was estimated based on a long-term NOEC for algae of $3.3 \mu \mathrm{g} / \mathrm{l}$ (see below). The risk assessment of endocrine disruptive chemicals (EDCs) has evolved markedly since the ERA was conducted, and further research into the endocrine disruptive properties of nonylphenol indicates that not all isomers are capable of inducing oestrogenic activity (Soares et al. 2008). If this is not accounted for in the experimental set up it can influence the NOEC, since a mix of isomers will result in lower exposure to the isomer that 
This is a post-print version of Syberg, K., \& Hansen, S. F. (2016). Environmental risk assessment of chemicals and nanomaterials - The best foundation for regulatory decision-making? Science of the Total Environment, 541, 784-794. The printed version of the paper is available at: DOI: 10.1016/j.scitotenv.2015.09.112

induces oestrogenic activity (i.e. the para-position isomer). It is furthermore debatable whether EDCs have thresholds or whether they should be treated as being similar to non-threshold genotoxins (EC 2013). If the latter is actually the case, a single para-position isomer would, in theory, be sufficient to cause risk. Lee et al. (2003) also found that nonylphenol has anti-androgenic properties, which illustrates that a threshold based on oestrogen-like properties alone might underestimate the real-life risk to populations that is a function of all endocrine disruptive properties. Nonylphenol has recently been re-evaluated under REACH, and based on this evaluation it was concluded that '4-Nonylphenol, branched and linear[...] are identified as substances of very high concern (SVHC) in accordance with Article 57 (f) of Regulation (EC) 1907/2006 (REACH) because they are substances with endocrine disrupting properties' (ECHA 2012). This case thus serves as an example of the limitations that the boundaries of our scientific understanding set for our ability to assess hazard. Today, it would be much more controversial to argue that endocrine disruptive properties are properly accounted for with the survival and growth type of endpoints.

\subsubsection{Non-standard tests vs. standard tests}

Another related discussion concerns whether data from non-standard tests that are more sensitive than standard tests should be used in ERAs for chemicals. In this respect, the focus has recently been on Bisphenol-A, whereby the US Food and Drug Administration and the European Food Safety Authorities were criticised for neglecting relevant scientific findings because they were not conducted under good laboratory practice (GLP) (Myers et al. 2009). A similar discussion is relevant for nonylphenol. In a 2013 hearing on the decision to classify nonylphenol as an SVHC, several stakeholders argued that the classification of nonylphenol as an EDC was not justified, since it was based on "poor" studies, as defined by the Klimisch score (ECHA 2013), an approach published by Klimisch et al. (1997) for evaluating experimental data for RAs. The principle is that studies are evaluated based on a number of parameters and then categorised within one of four categories, where categories 1 and 2 are considered 'reliable without and with restrictions', respectfully. Category 3 is considered 'not reliable', whereas category 4 studies are 
This is a post-print version of Syberg, K., \& Hansen, S. F. (2016). Environmental risk assessment of chemicals and nanomaterials - The best foundation for regulatory decision-making? Science of the Total Environment, 541, 784-794. The printed version of the paper is available at: DOI: 10.1016/j.scitotenv.2015.09.112

deemed 'not assignable’ (Klimisch et al. 1997). High emphasis is placed on studies conducted with standard protocols - and preferably under GLP. Among different responses the ECHA states that a non-monotonic dose-response relationship should not disqualify a study, since such relationships are documented for EDCs and thus should not be characterised as experimental artefacts (ECHA 2013). This illustrates that a very rigid interpretation of what constitutes reliable science may have a tendency to disqualify novel findings thus inhibiting well-timed decision-making.

\subsection{Dose response assessment of nonylphenol}

The second step in the ERA towards quantifying the hazardous potential of nonylphenol was the dose response assessment aimed at deriving PNECs. Two aspects of the 2002 ERA, which are addressed below, are of specific interest in the context of this paper.

\subsubsection{Dismissal of indicative studies and studies with unknown biological significance}

The lowest toxicity values for fish, invertebrates and algae (Table 1) formed the basis of the derived PNEC values, following the TGD procedure (EC 1993a). It is interesting to analyse the scientific foundation behind PNECs, in order to evaluate to what extent they are based on the 'high level of accuracy' that ERAs should provide (EC 2013).

A chronic NOEC for invertebrates of $24 \mu \mathrm{g} / \mathrm{l}$ originates from a daphnia reproduction study (Table 1), even though this study does not provide the lowest NOEC among the assessed studies. A study by Kahl et al. (1997) found NOEC in the range of 14-45 $\mu \mathrm{g} / \mathrm{l}$ for irregularly shaped egg masses, even though the effect was not statistically verified. However, since the biological significance of this observation was unknown, these data were not used further (EC 2002). In another study of the rainbow trout, Oncorhynchus mykiss, significant reductions in body weight were observed at $1 \mu \mathrm{g} / \mathrm{l}$ (Ashfield et al. 1998). Since this experiment was conducted with nominal concentrations, and experimental verifications of the concentrations were made, it was only used as an indicative study (EC 2002). The data used to determine the PNEC were 
This is a post-print version of Syberg, K., \& Hansen, S. F. (2016). Environmental risk assessment of chemicals and nanomaterials - The best foundation for regulatory decision-making? Science of the Total Environment, 541, 784-794. The printed version of the paper is available at: DOI: 10.1016/j.scitotenv.2015.09.112

$\mathrm{EC}_{10}$ of $3.3 \mu \mathrm{g} / \mathrm{l}$ from a chronic algae test with S. subspicatus (EC 2002), thus ensuring that the PNEC were lower than that derived from the egg mass study, albeit not the O. mykiss study.

Table 2. Top part: effect data from the studies that were used to derive PNECs in the European RA of nonylphenol. Bottom part: other scientific studies that could have altered the conclusion of the RA, if they had been available for consideration.

\begin{tabular}{|c|c|c|c|}
\hline \multirow{2}{*}{$\begin{array}{l}\text { Type of test species } \\
\text { Fish }\end{array}$} & Endpoints for short-term tests & \multicolumn{2}{|c|}{ Endpoints for long-term tests } \\
\hline & $\begin{array}{l}96 \mathrm{~h} \mathrm{LC}_{50}: \\
\text { (P. promelas) }\end{array}$ & $\begin{array}{l}33 \mathrm{~d} \text { NOEC }_{\text {survival }}: \\
\text { (P. promelas })\end{array}$ & $0.0074 \mathrm{mg} / \mathrm{l}$ \\
\hline Invertebrate & $\begin{array}{l}\text { 96h. } \text { EC }_{50}: \\
(\text { H. Azteca })\end{array}$ & $\begin{array}{l}21 \text { d. NOEC } \\
\text { (Durvival offspring: }\end{array}$ & $0.024 \mathrm{mg} / \mathrm{l}$ \\
\hline Algae & $\begin{array}{l}72 \text { h EC }_{50(\text { (biomass) }} \text { : } \\
\text { (S. subspicatus) }\end{array}$ & $\begin{array}{l}\left.72 \text { h EC }_{10(\text { biomass }}\right) \\
\text { (S. subspicatus) }\end{array}$ & $0.0033 \mathrm{mg} / \mathrm{l}$ \\
\hline \multicolumn{4}{|c|}{ Other relevant studies (post 1999) } \\
\hline SSD & \multicolumn{3}{|c|}{$\mathrm{HC}_{5}: 1.43 \mu \mathrm{g} / \mathrm{l}$ (freshwater) and $0.84 \mu \mathrm{g} / \mathrm{l}$ (seawater) Gao et al. (2014) } \\
\hline Genotoxicity & \multicolumn{3}{|c|}{ Photoactivated nonylphenol induce oxidative DNA damage (Okamoto et al. 2006) } \\
\hline Mixture effects & \multicolumn{3}{|c|}{ nonylphenol interact in mixtures causing deviation from additivity (Rajapakse et al. 2004) } \\
\hline EDC & \multicolumn{3}{|c|}{$\begin{array}{l}\text { Isomer specific oestrogen-like properties (Soares et al. 2008) } \\
\text { Anti-androgen properties (Lee et al. 2003) }\end{array}$} \\
\hline
\end{tabular}

\subsubsection{Disregarding real exposure to mixtures}

Yet another aspect that is not accounted for in the ERA is to what extent real-life exposure to mixtures containing nonylphenol affects the threshold for toxicity. Such mixture effects will vary depending on mixture composition, as shown by Rajapakse et al. (2004), who illustrate that PNECs based on single chemical ERAs are artefacts that do not reflect real-life toxicity. Oestrogenic effects, measured with the ESCREEN assay of a mixture containing nonylphenol, deviated from additivity, indicating that it could be problematic to assess mixture effects on the basis of single chemical toxicities (Rajapakse et al. 2004). In another study, Kwak et al. (2001) showed that the mixture effects of nonylphenol and Bisphenol-A were more potent than single chemicals when effects were measured with an array of EDC-sensitive endpoints in the viviparous fish Xiphophorus heller. These studies were published after the RA, but the problem caused by oestrogenic mixtures active substances had been highlighted earlier (Arnold et al. 1996), and participants in a US-EPA sponsored workshop concluded that mixture effects represented one of primary research focus areas for EDCs (Kavlock et al. 1996). Since the PNECs derived in the ERA are based on single toxicity studies, none of them can be said to account for the combined toxicity. 
This is a post-print version of Syberg, K., \& Hansen, S. F. (2016). Environmental risk assessment of chemicals and nanomaterials - The best foundation for regulatory decision-making? Science of the Total Environment, 541, 784-794. The printed version of the paper is available at: DOI: 10.1016/j.scitotenv.2015.09.112

\section{Hazard and dose-response assessments of Engineered Nanomaterials}

The environmental risks of nanomaterials have been subjected to increased levels of attention in recent years. Risk assessments have repeatedly been proposed by expert committees, policymakers, industry organisations and non-governmental organisations as the central means for informing decision makers about the risks of engineered nanomaterials (ENMs) (Nordan et al. 2006, SCENIHR 2007,US EPA 2007, ED \& DuPont 2007, CCA 2008, EFSA 2008, Hankin et al. 2011). An important question is therefore whether the existing ERA framework provides experimental tools that adequately ensure a proper scientific foundation for regulating ENMs within a reasonable period of time.

\subsection{Hazard identification of Engineered Nanomaterials}

4.1.1 Recognising ignorance about the hazard characteristics of emerging materials and substances,

\section{but still ignoring it}

When it comes to nanomaterials, there seems to be a general agreement that hazards depend on surface area, surface charge, surface chemistry, state of agglomeration as well as chemical composition (Hansen et al. 2007, Hankin et al. 2011), and especially surface area/reactivity has been mentioned as the newest "nanorelevant” properties for inclusion in hazard identification. This is in contrast to regular chemical risk assessments, which are based on the fact that chemical identity governs the fate and effects of a chemical.

However, all of the mentioned particle characteristics may affect the overall hazard, and since causal relationships still need to be discovered, further research is needed in this area before relevant data demands for hazard identification purposes can be defined. It is further discussed whether the unique properties of each type of nanoparticle make their hazard unique (Hansen et al. 2007; Hartmann et al. 2014). Toxicodynamics for hazards is yet another important area largely governed by uncertainty. Several studies have shown that the uptake and depuration of ENMs is different from results observed for other particles of similar metal composition (e.g. Dai et al. 2013, Khan et al. 2013). To what extent these differences influence the long-term toxicity of ENMs is still unknown, and this lack of understanding stresses the importance of 
This is a post-print version of Syberg, K., \& Hansen, S. F. (2016). Environmental risk assessment of chemicals and nanomaterials - The best foundation for regulatory decision-making? Science of the Total Environment, 541, 784-794. The printed version of the paper is available at: DOI: 10.1016/j.scitotenv.2015.09.112

defining the most relevant endpoints for determining ENM hazard. The equivocal identification of hazards for most nanoparticles is furthermore hampered by substantial limitations in our ability to determine individual and multiple particle characteristics simultaneously and in a consistent manner, both prior to and during tests, when using different characterisation techniques and/or across laboratories (RCEP 2008, JRC 2014).

All the unknowns about hazard characteristics have been well-recognised when it comes to nanomaterials, and this area could therefore be classified as 'recognised ignorance' (Hansen et al. 2013). Although they are often recognised in the few risk assessments that have been published (WHO 2013), the problem is that they are continuously ignored in these risk assessments when it comes to actual hazard identification, and so most often classical hazard characteristics are relied upon.

\subsubsection{Most sensitive endpoint?}

It is furthermore unclear as to whether or not we can rely on knowledge from industrial chemicals when selecting the most sensitive endpoints, since particle hazards have not been considered historically for risk assessment. As noted in the second REACH Implementation Project on Nanomaterials (RIP-oN 2) (Hankin et al. 2011), some novel endpoints and observations in fish and invertebrate tests may provide useful information when it comes to nanomaterials. For fish tests these novel endpoints included fish ventilation rates, gill pathologies, mucus secretion, brain pathology and animal behaviour based on the findings proffered by Schmidt (2007) and Federici et al. (2007). For invertebrates, Lovern et al. (2007) found that the heart rate, hopping frequency and appendage movement cycle frequency of daphnia were affected by exposure to nanomaterials, which again is not something normally considered in chemical risk assessment.

Therefore, it remains unknown as to whether or not the endpoints currently tested and reported on are actually the most sensitive or the most relevant examples, or whether new biological endpoints might actually be more relevant (RCEP 2008, Hartmann et al. 2014). 
This is a post-print version of Syberg, K., \& Hansen, S. F. (2016). Environmental risk assessment of chemicals and nanomaterials - The best foundation for regulatory decision-making? Science of the Total Environment, 541, 784-794. The printed version of the paper is available at: DOI: 10.1016/j.scitotenv.2015.09.112

\subsection{Dose-response assessment of Engineered Nanomaterials}

\subsubsection{When the mass-based dose does not make the poison}

Several ecotoxicological studies have reported dose-response relationships for tests with nanomaterials (Hund-Rinke and Simon 2006 and Heinlaan et al. 2008, Kühnel et al. 2009), whereas others have found none (Adams et al. 2006). It is therefore still debatable whether it is possible to establish reliable dose-response scenarios for ENM, due to a number of factors. First of all, nanomaterials have consistently been observed to be present in various environmental compartments in the form of individual primary particles as well as agglomerates and aggregates, whereas specific surface area is constant for individual particles and agglomerates, since the particles bind loosely together and aggregation causes a decrease in specific surface area due to the much stronger chemical bounds between the particles (Oberdörster et al. 2007, Aitken et al. 2011). It is well-known that aggregation and agglomeration are dependent on the coating and functionalisation of the nanomaterials, and that the level of agglomeration and aggregation varies between different test media due to a number of biotic and abiotic factors such as $\mathrm{pH}$, salinity, exposure to sunlight, stirring activities and the presence of natural organic matter. Although the latter is not normally considered an element of standardised ecotoxicological testing of chemicals, it might be very important for understanding agglomeration and aggregation behaviour in the environment itself (Fortner et al. 2005, Hartmann et al. 2014). For most nanomaterials there is a general hypothesis that ecotoxicity is linked to surface area (Dai et al. 2013), which might be due to increased surface reactivity and/or an increase in ion release from the surface as a function of the larger surface area. Normally, one would assume that the higher the concentration of nanoparticles, the higher the available specific surface area (SSA) and, subsequently, ecotoxicity, but this assumption is not necessarily true, as aggregate formation can be concentrationdependent, meaning that in the presence of a higher concentration of nanoparticles the likelihood of aggregation increases, thereby resulting in a decrease in available SSA. This means that we are likely to see increasing levels of ecotoxicity as concentrations of individual particles and agglomerates increase, but only until a certain level, when the concentration becomes so high that concentration-dependent aggregation is 
This is a post-print version of Syberg, K., \& Hansen, S. F. (2016). Environmental risk assessment of chemicals and nanomaterials - The best foundation for regulatory decision-making? Science of the Total Environment, 541, 784-794. The printed version of the paper is available at: DOI: 10.1016/j.scitotenv.2015.09.112

initiated and overall ecotoxicity decreases (Baun et al. 2009). This would mean that a traditional s-shaped dose-response relationship would not be observed, since more than one concentration would be linked to specific effect concentrations (e.g. EC50), thereby complicating the derivation of the PNEC. The hearing on the NP RA, described in the earlier case, illustrates that a move away from the monocausal relationship between concentration and effect lowers the credibility of the data - at least for some stakeholders.

\subsubsection{Limited exploration of other suitable dose descriptors}

Yet another aspect that complicates the dose-response assessment of ENM relates to particle hazards. Since there is no common agreement on the most important drivers for ENM hazards, it is debatable which metric is most suitable as a dose descriptor. Several alternatives to traditional mass have been proposed, such as surface area or number of particles, but only a few authors have actually investigated alternative metrics for expressing the dose. A number of studies have reported observing a size-dependent effect. Templeton et al. (2006), for instance, compared "as prepared"' and purified SWCNT and observed a difference in adverse effects in an estuarine copepod, which they attributed to a partly size-dependent and partly aggregation-dependent difference. For non-aggregating $\mathrm{SiO}_{2}$ nanoparticles, van Hoecke et al. (2008) showed that increasing effects on the growth rate of algae with decreasing particle sizes can be explained by an increase in specific surface area (van Hoecke et al. 2008). 1 
This is a post-print version of Syberg, K., \& Hansen, S. F. (2016). Environmental risk assessment of chemicals and nanomaterials - The best foundation for regulatory decision-making? Science of the Total Environment, 541, 784-794. The printed version of the paper is available at: DOI: 10.1016/j.scitotenv.2015.09.112

\section{5. The Origin of the Environmental Risk Assessment}

3 The cases above illustrate some of the challenges that ERAs face when it comes to hazard identification,

Key aspects of the risk assessment methodology, outlined in the Directives laying down the principles for risk assessing chemical substances and the TGD, such as PEC/PNEC-derivation, the use of extrapolation factors and the four steps of risk assessment, were introduced into the Directives and the first version of the TGDs from 1993 and 1994. Prior to 1993, discussions on how to assess the environmental risk of toxic chemicals had been going on in the United States of America and in many European countries such as Denmark, Germany, Spain and the Netherlands (van Straalen and van Leeuwen 2002). A thorough analysis of the scientific discussion in these historical documents can therefore provide a better understanding of the scientific foundation for the TGD - and thus the foundation of European environmental risk assessment. 
This is a post-print version of Syberg, K., \& Hansen, S. F. (2016). Environmental risk assessment of chemicals and nanomaterials - The best foundation for regulatory decision-making? Science of the Total Environment, 541, 784-794. The printed version of the paper is available at: DOI: 10.1016/j.scitotenv.2015.09.112

\subsection{The Dutch Health Council, minimal data requirements and reliable} procedures for the derivation of PNEC

In the Netherlands, the Health Council of the Netherlands established a scientific advisory committee to give advice on ecological risk assessments of chemicals (HCN 1989). In 1989, the council published an English version of its advice, termed “Assessing the risk of toxic chemicals for ecosystems," which provides insights into the now well-established minimal data requirements, the use of PNEC and the development of procedures for deriving PNEC.

The request for advice on ecological risk assessment, dating back to December 1987, came from the Minister of Welfare, Health and Cultural Affairs in the Netherlands, and the task of the committee was to assess "a procedure" to derive recommended values for ecosystems. The "procedure" had been proposed in August 1987 by an interdepartmental working party, "Risk Management for Ecosystems," and it outlined the minimum data required and the methods which would be applied to derive recommended values for (part of) ecosystems, despite limited knowledge. The proposal made by the working party involved recommendations in regard to water, soil and air, and although it is now almost four decades since their inception, these minimum data requirements and methods provide the backbone of existing chemical ERAs in the EU.

For water, the Working Party Risk Management for Ecosystems (1987) proposed that acute toxicity data for algae, daphnia and fish, according to the OECD test guidelines, are to be a minimum requirement. The lowest $\mathrm{LC}(\mathrm{E}) 50$ should then be compared with (expected or measured) exposure concentration. If the ratio is $>100$, a recommended value is to be derived by using the Kooijman (1985 and 1987), the Van Straalen (1987) and the Slooff et al. (1986) methods (Working Party Risk Management for Ecosystems 1987) (see Table 3). If the ratio is < 100, long-term experiments should be carried out, e.g. reproduction tests on daphnia and an egg larva test with fish according to OECD test guidelines, and the recommended value should be derived using the above methods (Working Party Risk Management for 
This is a post-print version of Syberg, K., \& Hansen, S. F. (2016). Environmental risk assessment of chemicals and nanomaterials - The best foundation for regulatory decision-making? Science of the Total Environment, 541, 784-794. The printed version of the paper is available at: DOI: 10.1016/j.scitotenv.2015.09.112

Ecosystems 1987). The approach was thus comparable to those used in current regulations (e.g. REACH), where risk quotients form a basis for assessing risk.

For soil, acute toxicity data are negligibly required for plants, earthworms and soil arthropods, whereas an inhalation test with a mammal, according to OECD guidelines, and fumigation experiments with plants and insects should be carried out for air quality. If a ratio $>100$, a recommended value is to be derived by using the Kooijman (1985 and 1987) and the Van Straalen (1987) methods. If the ratio is < 100, long-term experiments should be carried out with the abovementioned organisms, and the recommended value should be derived using the above methods as for water (Working Party Risk Management for Ecosystems 1987).

For mixture toxicity, it is noted that it is an important aspect of risk assessment but could not be taken into account at the time (i.e. August 1987) in the derivation of recommended values, because there are no instruments that deal properly with this problem, which again is noted as an undesirable situation (Working Party Risk Management for Ecosystems 1987).

The methods put forth by Kooijman (1985 and 1987), Van Straalen (1987) and Slooff et al. (1986) (see Table 3) play a very important role in the proposed procedure, and they were used to derive reliable procedures for extrapolating experimental data to environmental effects that the Health Council committee was asked to evaluate.

Table 3. Overview of the three extrapolation concepts that were the foundation of the Dutch committee's recommendations on how PNEC should be derived. The general approach and basic scientific foundations are listed.

\begin{tabular}{|c|c|c|c|}
\hline Name & Approach & Scientific foundation & Reference \\
\hline $\begin{array}{l}\text { Kooijman } \\
\text { method }\end{array}$ & $\begin{array}{l}\text { Extrapolate from } \mathrm{LC}_{50} \\
\text { values from most } \\
\text { sensitive species }\end{array}$ & $\begin{array}{l}\text { - HCS }{ }^{*} \text { derived from geometrical mean } \mathrm{LC}_{50} \text { value from } \\
\text { several species. } \\
\text { - HCS is divided with a safety factor that is dependent on } \\
\text { the number of species observed in the community. }\end{array}$ & Kooijman (1987) \\
\hline $\begin{array}{l}\text { Van Straalen } \\
\text { method }\end{array}$ & 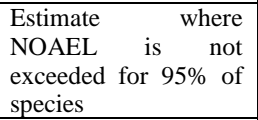 & $\begin{array}{l}\text { - HCS similar to Kooijman method is calculated, but } \\
\text { NOAEL }^{* *} \text { values are used instead of LC } \text { C }_{50} \text { values. } \\
\text { - Safety factor is constant, since the HCS is derived in } \\
\text { regard to } 95 \% \text { of all species in the ecosystem. }\end{array}$ & Van Straalen (1987) \\
\hline $\begin{array}{l}\text { Slooff et al. } \\
\text { method }\end{array}$ & 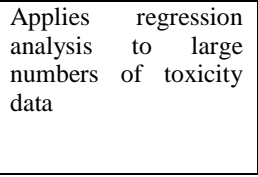 & $\begin{array}{l}\text { - Regression analysis allows for predictions of: } \\
\text { - LC } \mathrm{L}_{50} \text { effects on one species if the } \mathrm{LC}_{50} \text { is known for } \\
\text { another species. } \\
\text { - Chronic NOEC } \\
\text { - NOECeco }{ }^{* * * * *} \text { based on lowest } \mathrm{L}(\mathrm{E}) \mathrm{C}_{50} \text { or lowest chronic } \\
\text { NOEC. }\end{array}$ & Slooff et al. (1986) \\
\hline
\end{tabular}

\footnotetext{
* HCS: Hazardous concentration for sensitive species
} 
This is a post-print version of Syberg, K., \& Hansen, S. F. (2016). Environmental risk assessment of chemicals and nanomaterials - The best foundation for regulatory decision-making? Science of the Total Environment, 541, 784-794. The printed version of the paper is available at: DOI: 10.1016/j.scitotenv.2015.09.112

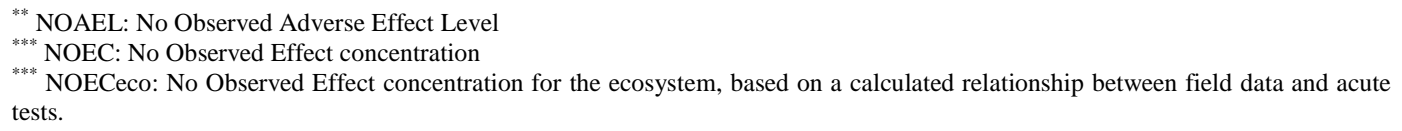

1) All methods offer some possibilities for including ecological aspects, for example in selecting test species and confidence limits.

The committee expressed serious objections to the applicability of the methods developed by the US EPA (1984) and Blanck (1984). In regard to the US EPA method, the committee objected to the use of the triangular (probabilistic) distribution of toxicity data, which implied the existence in ecosystems of concentration thresholds below which the probability of adverse effects are zero. This assumption the Committee found to be too rigorous (HCN 1989). Blanck (1984) used seven species whose EC50 values he had derived, and the committee found it to be an extremely drastic assumption that no species was capable of reacting more sensitively than these seven (HCN 1989).

Besides the conclusion related to methods for deriving reliable procedures for the number of aspects related to the proposed procedure and ecological risk assessment. 
This is a post-print version of Syberg, K., \& Hansen, S. F. (2016). Environmental risk assessment of chemicals and nanomaterials - The best foundation for regulatory decision-making? Science of the Total Environment, 541, 784-794. The printed version of the paper is available at: DOI: 10.1016/j.scitotenv.2015.09.112

First, they noted that the purpose of the procedure was to predict the effects of toxic chemicals on ecosystems and to establish boundary conditions for the protection of ecosystems despite the limited

Second, the key to making such an assessment, according to the committee, was the extrapolation from experimental data to effects in ecosystems. The proposed procedure and risk assessment thus aimed at protecting the characteristics of the species composition of the ecosystem but, according to the committee, it was not possible to conclude from the available data whether an ecosystem would react more sensitively to a toxic chemical than individual species. The committee stressed that no safe values could be derived with the procedure but only limits above which certain effects would occur (HCN 1989).

Finally, the committee discussed to what extent a risk assessment can make scientifically certain recommendations to policymakers. The committee concluded that none of the reviewed ERA procedures could claim to safeguard ecosystems against the adverse effects of toxic chemicals. However, they provided a first impetus to putting present knowledge to use in a practical way for the protection of ecosystems (HCN 1989). The committee stated that a complete scientific foundation for risk regulation was not possible, and policy could therefore not be based on such a requirement (HCN 1989). The committee also highlighted some areas that were not covered properly in any of the approaches, concluding that the risk assessment procedure could not be applied in the case of mixed toxic chemicals or for carcinogenic or mutagenic chemicals (HCN 1989). The committee recommended that the effects of exposure to chemical mixtures should be included as far as possible (HCN 1989).

Advice from the Health Council was later implemented in the Netherlands in the form of a policy paper on risk management and fed into processes that were going on at the time at the OECD and in the EU (HCN 1989, Premises for Risk Management 1989; OECD 1992; Straalen and van Leeuwen (2002)). 
This is a post-print version of Syberg, K., \& Hansen, S. F. (2016). Environmental risk assessment of chemicals and nanomaterials - The best foundation for regulatory decision-making? Science of the Total Environment, 541, 784-794. The printed version of the paper is available at: DOI: 10.1016/j.scitotenv.2015.09.112

\subsection{The OECD, the US EPA and three tiers of extrapolation factors}

The three tiers of extrapolation factors represent another key aspect of the environmental risk assessment framework and helps explain the systemic challenges that we have observed in the case of nonylphenol and nanomaterials. In the early 1990s, transatlantic dialogue was initiated also under the umbrella of the Hazard Assessment Advisory Board of the Organisation for Economic Co-operation and Development (OECD). When it comes to risk assessment, the proceedings of an OECD workshop in Arlington, USA, are noteworthy, as they were published at the same time as the TGDs were being prepared (OECD 1992). The aim of the workshop was to present state-of-the-art extrapolation methods, to identify areas of uncertainty and to reach consensus on practical, available and validated extrapolation methods (OECD 1992). According to van Straalen and van Leeuwen (2002), the methodology was implemented on a wider scale after the OECD workshop.

Participants in the OECD workshop recommended three tiers of extrapolation factors, each with a factor of ten. The derivation of the three assessment factors was based on empirical experience rather than a theoretical model. The approach was inspired by the approach that the US EPA (1984) had developed in 1984, published in a report named "Estimating concern levels for concentrations of chemical substances in the environment” (US EPA 1984), in which they evaluated how uncertainty can be addressed by applying assessment factors (AF). The publication discussed the scientific rationale behind applying four tiers of AF (Table 4), which have subsequently become more or less standardised AFs for environmental risk assessment. The authors stressed that using AFs did not identify a safe exposure level in ecological risk assessment (comparable to considerations made by the Dutch committee on risk assessment analysed above), and thus it was not directly comparable to the margin of safety (MOS) derived for human health RAs (US EPA 1984). An MOS is used when there is sufficient data to determine a safe level of use, whereas AFs are used when data are absent. The AF was created to account for many experimental and environmental factors that alter test results away from field-level effects, but due to convenience all these differences were grouped 
This is a post-print version of Syberg, K., \& Hansen, S. F. (2016). Environmental risk assessment of chemicals and nanomaterials - The best foundation for regulatory decision-making? Science of the Total Environment, 541, 784-794. The printed version of the paper is available at: DOI: 10.1016/j.scitotenv.2015.09.112 purposes of ease and simplicity, all AFs were also rounded off to the nearest power of ten (US EPA 1984).

3 Table 4: The three assessment factors recommended by the US EPA as a means of handling extrapolation

4 from different data scenarios to real life.

\begin{tabular}{|c|c|c|c|}
\hline Categories & Level of scientific data at hand & Recommended AF & Scientific rationale \\
\hline & Field data & 1 & $\begin{array}{l}\text { Field studies measure effects that are expected to } \\
\text { occur in natural environments. }\end{array}$ \\
\hline $\begin{array}{l}\text { Laboratory- } \\
\text { to-field }\end{array}$ & LOEC based on chronic study & 10 & $\begin{array}{l}\text { a) Other species may be more sensitive. } \\
\text { b) Test conditions may not represent natural } \\
\text { environment. } \\
\text { c) Other effects may occur at lower levels. } \\
\text { d) The presence of other chemicals in the } \\
\text { environment may amplify the effect. }\end{array}$ \\
\hline $\begin{array}{l}\text { Acute-to- } \\
\text { chronic }\end{array}$ & $\begin{array}{l}\text { LOEC based on many acute } \\
\text { concentrations }\end{array}$ & 100 & $\begin{array}{l}\text { e) At least one acute test for each of the three } \\
\text { taxonomic groups (fish, invertebrates, algae) or } \\
\text { f) At least five acute tests divided among two of } \\
\text { the three taxonomic levels. } \\
\text { g) Use of juvenile organisms can underestimate } \\
\text { effects on eggs and embryos. }\end{array}$ \\
\hline $\begin{array}{l}\text { Species-to- } \\
\text { species }\end{array}$ & One acute concentration or QSAR & 1000 & $\begin{array}{l}\text { h) No one or two species are consistently more } \\
\text { sensitive to a broad array of chemicals. } \\
\text { i) Actual vs. estimated (QSARs) LC } 50 \text { value may } \\
\text { vary up to } 10 \text { fold. }\end{array}$ \\
\hline
\end{tabular}

The scientific rationale behind these three categories of AFs is blurry. In order to have a species-to-species ratio of 10, the US EPA (1984) argued that data from three fish species (e.g. fathead minnow) and two crustacean species (e.g. Daphnia magna) were largely representative of all relevant species' sensitivity. It was further argued that test requirements could therefore be limited to fish and crustaceans (the so-called “cluster concept”), since it was not reasonable to require tests for all relevant species. Algae were subsequently added as a third group, even though no specific data support the inclusion (US EPA 1984). For the acute-to-chronic ratio (ACR), it was concluded that the data supported an additional AF of 10 despite substantial variations (US EPA 1984). The largest ratio reported was 17.551 for the herbicide Propanil, which was tested on fathead minnow (Call et al. 1983). On a more general level a statistical study of 95 chemicals showed that the median ACR was 8.46, leading to the conclusion that a factor of 10 represented “typical” ACRs. 
This is a post-print version of Syberg, K., \& Hansen, S. F. (2016). Environmental risk assessment of chemicals and nanomaterials - The best foundation for regulatory decision-making? Science of the Total Environment, 541, 784-794. The printed version of the paper is available at: DOI: 10.1016/j.scitotenv.2015.09.112

limited, and the US EPA described the outcome of the process comparing field to acute $\mathrm{LC}_{50}$ data as a working model, for which further data were needed to refine the projections. With the knowledge they had at hand they found a factor of 1000 from acute-to-field to be reasonable. QSAR data were evaluated as being comparable to acute $\mathrm{LC}_{50}$ data within one order of magnitude, and it was therefore recommended as being treated as being equal to a single $\mathrm{LC}_{50}$. A final interesting detail in regard to the initial development of AFs is that the authors explicitly pointed out that further research should improve and refine them (US EPA 1984). It may seem that this recommendation has been forgotten, though, since it was made more than three decades ago.

If a large dataset from long-term tests for different taxonomic groups is available, the use of the species sensitivity distribution (SSD) method is currently perceived as less uncertain compared to the extrapolation from data from the base set of test organisms, and an AF of between 5-1 can be used, if justification is provided (ECHA 2008). Participants in the OECD workshop in 1992 also discussed a relatively large dataset focused on the use of species sensitivity distribution (SSD) methods and regression models. SSD or NOECs were proposed as alternatives to the subjective assessment factors that were otherwise used to extrapolate from small datasets. Despite the recognition that SSD provides a better scientific foundation for hazard evaluation, the derived safe concentrations may not protect all functions of the ecosystem, due to a number of scientific assumptions: a) species in ecosystems can be divided into a small group consisting of every sensitive species and a large group including the less sensitive species; b) the distribution of sensitivity in lab approximates distribution in the ecosystem; c) the sensitivity of a species isolated in a lab is equal to its sensitivity in a complex ecosystem; d) sensitivity can be characterised as (normal) distribution, and such a characterisation made under laboratory conditions can be directly extrapolated to field conditions and e) interactions between species are not accounted for when applying SSDs, and because an SSD is based on existing standard tests the protection level depends on the relationship between these tests and their biological and ecological significance, which can be limited (OECD 1992). 
This is a post-print version of Syberg, K., \& Hansen, S. F. (2016). Environmental risk assessment of chemicals and nanomaterials - The best foundation for regulatory decision-making? Science of the Total Environment, 541, 784-794. The printed version of the paper is available at: DOI: 10.1016/j.scitotenv.2015.09.112 factor to be used on mesocosm studies, or (semi-) field data, needs to be reviewed on a case-by-case basis. evaluations. This is the first time that the OECD report has addressed a risk scenario as is it generally understood today (i.e. as the ratio obtained by dividing hazard and exposure assessments), noting that standard laboratory tests cannot predict effects on the ecosystem level due to, for instance, the influence of 9 interspecies interactions, the indirect effects of chemicals, effects on ecosystem processes and recovery rates

10 and finally the cumulative effects of multiple stressors. Even though these considerations are more than 20 11 years old, some of them are still relevant - as seen in the case studies on nonylphenol and nanoparticles. 
This is a post-print version of Syberg, K., \& Hansen, S. F. (2016). Environmental risk assessment of chemicals and nanomaterials - The best foundation for regulatory decision-making? Science of the Total Environment, 541, 784-794. The printed version of the paper is available at: DOI: 10.1016/j.scitotenv.2015.09.112

\section{Discussion}

Our analysis of the two case studies illustrates some of the challenges that ERAs face when it comes to assessing chemicals and nanomaterial risk. Based on the nature of these identified challenges, we would argue that they cannot be addressed by revising the ERA; instead, they are a reflection of the fundamental limitations of the ERA framework, and these limitations have been well recognised over time but never really addressed in regulatory application.

\subsection{Hazard identification}

In the case of nonylphenol and nanoparticles, we identified a number of challenges, including the disregard for endocrine-disrupting effects and "new" endpoints in favour of traditional endpoints, as well as the disregard for findings stemming from non-standard tests in favour of standard tests.

From the case of nonylphenol it is clear that if there are indications that a chemical has properties of very high (or unknown) concern, such as EDCs and carcinogens, it should not be overlooked, even if it seems that other endpoints are more sensitive - especially if the scientific understanding is still in the development phase. In the 2002 ERA for nonylphenol it was concluded that oestrogenic properties are covered by the most sensitive endpoint (a 72h algae growth test) (EC 2002). Since the collection of data for the ERA was finalised in 1999, new studies have been published, as a function of scientific progress, which have led the European Chemical Agency to propose that nonylphenol be classified as SVHC, based on its ED properties (ECHA 2012). We do not highlight this development in order to insinuate that the 2002 ERA was not conducted properly; the work with the 2002 nonylphenol ERA was indeed comprehensive and lived up to the standards that can be expected from such an assessment. However, the case serves as an example of the limitations that the boundaries of our scientific understanding set on our ability to assess risk, if we insist that risk must be quantified with standardised assays. Today it would be much more controversial to argue 
This is a post-print version of Syberg, K., \& Hansen, S. F. (2016). Environmental risk assessment of chemicals and nanomaterials - The best foundation for regulatory decision-making? Science of the Total Environment, 541, 784-794. The printed version of the paper is available at: DOI: 10.1016/j.scitotenv.2015.09.112

that disruptive endocrine properties are properly accounted for through the survival and growth type of endpoints. A valuable lesson in this regard is that we should not disregarded studies that show the effects of unknown biological importance at very low concentrations but rather highlight any uncertainty in determining the importance of such findings.

In regard to the case of ENM it remains to be discovered whether there are nano-specific effects that are not properly accounted for within the current ERA framework, though it is still too early to conclude that the existing framework is sufficient (WHO 2013, Scientific committees 2013). Limits to our understanding of such nano-specific effects, as well as limitations in regard to our technological capabilities, result in high amounts of uncertainty in any ENM hazard identification. This makes it questionable whether we are able to provide evidence-based assessments of ENM hazards that can be used to quantify risk. Looking at the hindsight lessons taken from the ERA of nonylphenol, it might not feasible to rely on ENM hazard data until we are more certain about the best suitable approach for such hazard identifications. It would therefore seem feasible if the search for novel findings were better and more systematically integrated in the risk assessment process, not least in regard to new and emerging risks such as those from ENMs.

The preference for traditional endpoints and standard tests is not something that is specific to nonylphenol and nanoparticles - it can be traced back to the origins of ERAs in the EU. The endpoints that the Working Party Risk Management for Ecosystems in the Netherlands proposed and asked for back in 1989 regarded acute toxicity and long-term experiments such as reproduction tests on daphnia and an egglarva test for fish. Preferences for such quite crude endpoints have led over time to the unfortunate dismissal of indicative studies of new endpoints as well as studies with unknown biological significance. This could explain the reluctance to accept endocrine-disrupting effects and "new" versus traditional endpoints in the 2002 ERA of nonylphenol. Similarly, from the outset, the Working Party Risk Management for Ecosystems (1987) referred to OECD standard test guidelines, thereby giving priority to standardised tests over nonstandard tests. 
This is a post-print version of Syberg, K., \& Hansen, S. F. (2016). Environmental risk assessment of chemicals and nanomaterials - The best foundation for regulatory decision-making? Science of the Total Environment, 541, 784-794. The printed version of the paper is available at: DOI: 10.1016/j.scitotenv.2015.09.112

The minimum data requirements posited by the Working Party Risk Management for Ecosystems (1987) for air, water and soil are the same as those that are used in REACH, which again could help explain resistance to accepting endocrine-disrupting effects and "new" endpoints versus the more traditional examples that have now become the norm. Furthermore, it also explains why there is a tendency to ignore aspects that have been recognised as "known unknowns" (i.e. uncertainties that we are aware of but are unable to address properly) when it comes to the hazard characteristics of emerging materials and substances. In order to provide the best scientific foundation for risk management, such uncertainties should therefore be highlighted rather than ignored.

\subsection{Dose-response assessment}

Prior to 1993, discussions on how to assess the environmental risk of toxic chemicals were taking place in the United States of America and in many European countries, such as Denmark, Germany, Spain and the Netherlands (van Straalen and van Leeuwen 2002). Especially the work conducted by the US EPA (1984) and in the Netherlands laid the foundations for the chemical RA framework. The Health Council of the Netherlands established a scientific advisory committee to give advice on the ecological risk assessment of chemicals, and in 1989, this committee published the report "Assessing the risk of toxic chemicals for ecosystems" (HCN 1989) in which minimal data requirements, the use of the term "PNEC" and the development of procedures for the derivation of PNEC, which are well established now, were described.

Although the HCN (1989) defined the minimum data requirements, over time these have become standard data requirements, and very seldom are other data considered in the final dose-response assessment. This has led to the dismissal of indicative studies and studies with unknown biological failed to identify the most sensitive species as well as limitations in the use of extrapolation methods. 
This is a post-print version of Syberg, K., \& Hansen, S. F. (2016). Environmental risk assessment of chemicals and nanomaterials - The best foundation for regulatory decision-making? Science of the Total Environment, 541, 784-794. The printed version of the paper is available at: DOI: 10.1016/j.scitotenv.2015.09.112

These limitations of the ERA method were well-recognised by the experts that suggested the approach back in the late 1980s. The committee noted that the purpose of the procedure was to predict the effects of toxic chemicals on ecosystems and to establish boundary conditions for the protection of these ecosystems, despite limited scientific knowledge available at the time on ecotoxicology (HCN 1989). They also noted that the key to making such assessments was extrapolation from experimental data to effects in ecosystems. To obtain sufficient protection this requires that data are derived from tests on the most sensitive species in the ecosystem. Ecological risk assessments aim at protecting the characteristics of the species composition of the ecosystem rather than all individual species. According to the committee, it was not possible to conclude from the available data whether an ecosystem would react more sensitively to a toxic chemical than individual species (HCN 1989). Hence, there was no certainty that protecting individual species would lead to the protection of the entire ecosystem, so the risk assessment paradigm fundamentally aimed at protecting species and not ecosystems (HCN 1989). The committee concluded that none of the RA procedures reviewed could lay claim to safeguarding ecosystems against the adverse effects of toxic chemicals. Furthermore, the committee stated that complete scientific foundation for risk regulation was not possible, and policy should therefore not be based on such a requirement (HCN 1989). The advice from the Health Council was later implemented in the Netherlands in the form of a policy paper on risk management (HCN 1989, Premises for Risk Management 1989) and subsequently implemented in the Technical Guidance Documents (EC 2003) and the Guidance documents used under REACH (ECHA 2008).

Several aspects in regard to dose-response assessment and subsequent PNEC derivation are relevant to discuss when it comes to mixtures. It is well documented that mixture toxicity often exceeds the toxicity of individual components in the mixture (e.g. Levis 1992, Syberg et al. 2009, Kortenkamp et al. 2009). The Dutch Working Party Risk Management for Ecosystems noted that mixture toxicity is an important aspect of risk assessment, and it was further noted that mixtures could not be taken into account at the time (i.e. August 1987), since there were no instruments that could deal properly with this problem, which again was noted to be an undesirable situation (Working Party Risk Management for Ecosystems 
This is a post-print version of Syberg, K., \& Hansen, S. F. (2016). Environmental risk assessment of chemicals and nanomaterials - The best foundation for regulatory decision-making? Science of the Total Environment, 541, 784-794. The printed version of the paper is available at: DOI: 10.1016/j.scitotenv.2015.09.112

1987). Despite this recognition, back in the late 1980s, and empirical evidence on the importance of mixture toxicity that has built up over decades, RAs are primarily carried out solely for single chemicals (EC 2003, EC 2006). The nonylphenol risk assessment serves as an illustration of this problem, since mixture effects are not quantified at all in this RA. Even though mixture toxicity is a complex challenge, solutions have been discussed over the last decades, and have recently been reviewed in (Kortenkamp et al. 2009).

\subsection{Improving scientific foundation and ensuring timely protection}

Our analysis demonstrates that the ERA framework should rather be considered as a pragmatic set of tools that provides a systematic approach to determining risk rather than an evidence-based foundation for decision making. There are several areas where it fails to provide evidence of the real-life hazards of chemicals and nanomaterials, as discussed above. Apart from these gaps there is also a tendency for ERAs to focus too rigidly on achieving transparency and reliability through demands for GLP and standard tests (Myers et al. 2009). Whereas such demands make good sense in relation to data provided by industry, they nevertheless pose a problem in regard to data produced by academia and published in peer-reviewed journals. GLP was introduced to ensure high quality data produced by industry, but the scientific literature already has such a system in place (i.e. the peer review system). There are several problems with this approach that our analysis helps to illuminate. First of all, the most important role of science is to address new questions and to generate a novel understanding of complex issues. If such novel findings are not accounted for, ERAs may fail to provide the foundation for precautionary preventive action as required by the European Treaty (EU 2007). Both the nonylphenol and the ENM cases are illustrations of this problem. Even though the nonylphenol ERA was finalised in 2002 (EC 2002), a recommendation for classifying the compound as SVHC was not made until 2012 (ECHA 2012). And even at this point some the European Council for Alkylphenols and Derivatives argued that it was premature to classify nonylphenol as an SVHC based on its endocrine-disruptive properties, since no general EDC definition was agreed upon (ECHA 2013). A possible alternative to this prolongation of the decision-making process would have been to 
This is a post-print version of Syberg, K., \& Hansen, S. F. (2016). Environmental risk assessment of chemicals and nanomaterials - The best foundation for regulatory decision-making? Science of the Total Environment, 541, 784-794. The printed version of the paper is available at: DOI: 10.1016/j.scitotenv.2015.09.112

conduct a chemical alternative assessment (CAA) (Lavoie et al. 2010) at a much earlier stage. The outcome of a CAA is meant to provide stakeholders with an assessment of alternatives to the chemicals in question, thus facilitating the substitution process (Lavoie et al. 2010). Illuminating such substitution pathways seems to be a good and viable step in ensuring more timely decision making and therefore protection. This approach would be more in line with commitments under the European Treaty to ensure precautionary preventive action.

For ENMs we still rely on ERAs to provide the foundation for decision making, even though it is generally accepted that our ability to assess ENM hazards and subsequently PNECs is poor. It is therefore relevant to call attention to the fact that ERAs should not be considered as a "holy grail" for informing decision making but rather be used as one particular tool in a larger decision-making toolbox. Interestingly, the US EPA (1992) discusses the relationship between the risk assessor and the risk manager something not normally considered in the EU when it comes to discussions about risk assessment, and definitely something from which European decision-makers could learn. In this discussion it is stated that “The results of the risk assessment serve as input to the risk management process, where they are used along with other inputs defined in EPA statutes, such as social and economic concerns, to evaluate risk management options" (US EPA 1992). It is, however, paramount that the foundation for management is presented in a very transparent manner, as this will ensure that it is clear if socio economic interests are perceived as more important than a specified risk, or if uncertainties regarding the actual risk prevent a reliable assessment of risk. Such transparency is needed if stakeholders and the public are to have the ability to judge if risk assessors live up to their political mandate.

Our analysis shows the derivations of PNECs with ERAs are governed substantially by pragmatic decisions, even for substances that can be properly assessed within the ERA framework. When uncertainties that are linked specifically to ENMs are considered along with the limited scientific foundation for the assessment factors applied, it seems questionable whether ERAs can provide the 'evidence-based foundation' for decision making that the framework is expected to deliver (Löfsted 2011). There is no doubt 
This is a post-print version of Syberg, K., \& Hansen, S. F. (2016). Environmental risk assessment of chemicals and nanomaterials - The best foundation for regulatory decision-making? Science of the Total Environment, 541, 784-794. The printed version of the paper is available at: DOI: 10.1016/j.scitotenv.2015.09.112

that science is progressing within this field and that the work in understanding ENM hazards and subsequent risk should continue, but until the uncertainties within this field have been further limited it would be more feasible to let decision making rely on alternative frameworks that also include other societal considerations, as mentioned by the US EPA (1992), as well as scientific evaluations that acknowledge uncertainty rather than ignore it and ethical discussions conducted in the light of the precautionary principle.

A final note in this paper concerns transparency. None of the methodologies mentioned here can be said to provide a rigorous scientific solution to inform decision-making. This fact stresses the point that regulatory action is a political responsibility, and so in order for science to help inform such political decisions, transparency is paramount. While the European Commission's European Chemical Bureau focused on updating the TGD in 1996 and in 2003, the US EPA (1998) focused on 'new approaches to complex risk problems by delineating the need for "planning and problem formulation" to address technically challenging assessments of ecosystems, chemical mixtures, and cumulative risk’ (US EPA 1998). An important aspect of this approach is that stakeholders are involved in the initial stages of the assessment. Although this approach might not lead to a more accurate estimation of the PNEC, it does provide for better decision support, as it delivers a more in-depth and transparent evaluation of a given risk as well as the pros and cons of various management options.

\section{Acknowledgements}

We wish to thank Dr. Jette Rank and Prof. Anders Baun for their constructive dialogue and feedback on the manuscript at various stages. The work by KS was supported by the Villum Foundation (Project VKR022070). The work by SFH is part of the project ENVNANO (Environmental Effects and Risk Evaluation of Engineered Nanoparticles), supported by the European Research Council (Grant no. 281579). 
This is a post-print version of Syberg, K., \& Hansen, S. F. (2016). Environmental risk assessment of chemicals and nanomaterials - The best foundation for regulatory decision-making? Science of the Total Environment, 541, 784-794. The printed version of the paper is available at: DOI: 10.1016/j.scitotenv.2015.09.112

\section{References}

2

Adams, L.K., Lyon, D.Y., Alvarez, P.J.J., 2006. Comparative eco-toxicity of nanoscale TiO2, SiO2, and ZnO water suspensions. Water Res. 40, 3527-3532

Aitken, R.A, Bassan, A., Friedrichs, S., Hankin, S.M., Hansen, S.F., Holmqvist, J., Peters, S.A.K., Poland, C.A., Tran, C.L. 2011. Specific Advice on Exposure Assessment and Hazard/Risk Characterisation for Nanomaterials under REACH (RIP-oN 3) Final Project Report . Document reference RNC/RIP-

oN3/FPR/1/FINALBrussels: European Commission. Available:

http://ec.europa.eu/environment/chemicals/nanotech/pdf/report_ripon3.pdf

Arnold, S.F., Klotz, D.M., Collins, B.M., Vonier, P.M., Guillette Jr., L.J., McLachlan, J.A. 1996. Synergistic activation of estrogen receptor with combinations of environmental chemicals. Science, 272 (5267), pp. 1489-1492.

Ashfield, L.A., Pottinger, T.G., Sumpter, J.P. 1998. Exposure of female juvenile rainbow trout to alkylphenolic compounds results in modifications to growth and ovosomatic index. Environ. Toxicol. Chem. 17(4), 1552-8618

Baun, A., Hartmann, N.B, Greiger, K.D., Hansen, S.F. 2009. Setting the Limits for Engineered Nanoparticles in European Surface Waters. Journal of Environmental Monitoring 11, 1774 - 1781.

Blanck, H. Species dependent variation among organisms in their sensitivity to chemicals. 1984. Ecological Bulletins 36, 107-119

Call, D.J., Brooke, L.T., Raymond, J.K., Knuth, M.L., Anderson, C., Moriarity, C. 1983. Toxicity, bioconcentration, and metabolism of the herbicide Propanil (3',4'-dichloropropionanilide) in freshwater fish. Arch Environ Contam Toxicol. 12, 175-182

CCA. 2008. Small Is Different: A Science Perspective On The Regulatory Challenges of the Nanoscale. Ottawa: The Council of Canadian Academies, Ottawa, Canada 
This is a post-print version of Syberg, K., \& Hansen, S. F. (2016). Environmental risk assessment of chemicals and nanomaterials - The best foundation for regulatory decision-making? Science of the Total Environment, 541, 784-794. The printed version of the paper is available at: DOI: 10.1016/j.scitotenv.2015.09.112 Dai, L., Syberg K., Banta, G.T., Selck, H., Forbes, V.E. 2013.Effects, Uptake, and Depuration Kinetics of

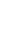
Chem Eng, 1(7), 760-767

EC 1993a. Technical guidance documents in support of the risk assessment Directive (93/67/EEC) for new substances notified in accordance with the requirements of Council Directive 67/548/EEC. European Commission, Bruxelles, Belgium

EC 1993b. Commission directive 93/67/EEC of 20 July 1993 laying down the principles for assessment of risks to man and the environment of substances notified in accordance with Council Directive 67/548/EEC. European Commission, Bruxelles, Belgium

EC 1994. Technical guidance documents in support of the risk assessment Regulation (1488/94) for existing substances in the context of Council Regulation 793/93/EEC. European Commission, Bruxelles, Belgium

EC 2000. Directive 2000/60/EC of the European Parliament and of the Council of 23 October 2000 establishing a framework for Community action in the field of water policy. European Commission, Bruxelles, Belgium

EC 2002. European Union Risk Assessment Report. 4-Nonylphenol (Branched) and Nonylphenol. CAS Nos: 84852-15-3 and 25154-52-3 EINECS Nos: 284-325-5 and 246-672-0. Environment Agency Chemicals Assessment Section. Oxfordshire, United Kingdom. Can be accessed at: http://echa.europa.eu/documents/10162/43080e23-3646-4ddf-836b-a248bd4225c6

EC 2003. Technical Guidance Document on Risk Assessment in support of Commission Directive 93/67/EEC on Risk Assessment for new notified substances, Commission Regulation (EC) No 1488/94 on Risk Assessment for existing substances, Directive 98/8/EC of the European Parliament and of the Council concerning the placing of biocidal products on the market. European Commission, Joint Research Center, Ispra, Italy. 
This is a post-print version of Syberg, K., \& Hansen, S. F. (2016). Environmental risk assessment of chemicals and nanomaterials - The best foundation for regulatory decision-making? Science of the Total Environment, 541, 784-794. The printed version of the paper is available at: DOI: 10.1016/j.scitotenv.2015.09.112

EC 2006. Regulation (EC) No 1907/2006 of the European Parliament and of the Council of 18 December 2006 concerning the Registration, Evaluation, Authorisation and Restriction of Chemicals (REACH), establishing a European Chemicals Agency, amending Directive 1999/45/EC and repealing Council Regulation (EEC) No 793/93 and Commission Regulation (EC) No 1488/94 as well as Council Directive 76/769/EEC and Commission Directives 91/155/EEC, 93/67/EEC, 93/105/EC and 2000/21/EC. European Commission, Bruxelles, Belgium

EC 2012. Regulation (EU) No 528/2012 of the European Parliament and of the Council of 22 May 2012 concerning the making available on the market and use of biocidal products. European Commission,

Bruxelles, Belgium

EC 2013. Minutes of the expert meeting on endocrine disruptors. Meeting on endocrine disruptors . Office of the Chief Scientific Adviser, European Commission, Brussels, Belgium.

ECHA 2008. Guidance on information requirements and chemical safety assessment Chapter R.10:

Characterisation of dose [concentration]-response for environment. Europeans Chemicals Agency, Helsinki, Finland

ECHA 2012. Support document for identification of 4-Nonylphenol, Branched and linear, Ethoxylated as substances of very high concern because, due to their degradation to substances of very high concern (4Nonylphenol, Branched and linear) with endocrine disrupting properties, they cause probable serious effects to the environment which gives risk to an equivalent level of to those of CMR and PBT/vPvB substances. ECHA, Helsinki, Finland.

ECHA 2013. Comments on an Annex XV dossier for identification of a substance as SVHC and response to these comments - 4-Nonylphenol, branched and linear, ethoxylated [substances with a linear and/or branched alkyl chain with a carbon number of 9 covalently bound in position 4 to phenol, ethoxylated covering UVCB- and well-defined substances, polymers and homologues, which include any of the individual isomers and/or combinations thereof]. ECHA, Helsinki, Finland. 
This is a post-print version of Syberg, K., \& Hansen, S. F. (2016). Environmental risk assessment of chemicals and nanomaterials - The best foundation for regulatory decision-making? Science of the Total Environment, 541, 784-794. The printed version of the paper is available at: DOI: 10.1016/j.scitotenv.2015.09.112

ECHA 2014. Draft background document for 4-Nonylphenol, branched and linear, ethoxylated (4-NPnEO). European Chemicals Agency, Helsinki, Finland.

ED \& Dupont 2007. Nano Risk Framework. Environmental Defense - DuPont Nano Partnership. Washington DC, USA

EEA 2001. Late lessons from early warnings: the precautionary principle 1896-2000. Environmental issue report No 22/2001. European Environmental Agency, Copenhagen, Denmark

EEA 2013. Late lessons from early warnings: science, precaution, innovation. EEA Report No 1/2013. European Environmental Agency, Copenhagen, Denmark

EFSA 2008. Draft Opinion of the Scientific Committee on the Potential Risks Arising from Nanoscience and Nanotechnologies on Food and Feed Safety (Question No EFSAQ-2007-124). European Food Safety Authority, Bruxelles, Belgium

EU 2007. The Lisbon Treaty. The Treaty on European Union and the Treaty on the Functioning of the European Union. European Union, Bruxelles, Belgium

Federici, G., Shaw, B., Handy, R. 2007. Toxicity of titanium dioxide nanoparticles to rainbow trout (Oncorhynchus mykiss): Gill injury, oxidative stress, and other physiological effects. Aquatic Toxicology $84(4), 415-430$

Fortner, J. D., Lyon, D. Y., Sayes, C. M., Boyd, A. M., Falkner, J. C., Hotze, E. M., Alemany, L. B., Tao, Y. J., Guo, W., Ausman, K. D., Colvin, V. L., Hughes, J. B. 2005. C-60 in water: Nanocrystal formation and microbial response. Environ Sci Technol. 39(11), 4307-4316

Gao, P., Li, Z., Gibson, M., Gao, H-.2014. Ecological risk assessment of nonylphenol in coastal waters of China based on species sensitivity distribution model. Chemosphere. 104, 113-119 
This is a post-print version of Syberg, K., \& Hansen, S. F. (2016). Environmental risk assessment of chemicals and nanomaterials - The best foundation for regulatory decision-making? Science of the Total Environment, 541, 784-794. The printed version of the paper is available at: DOI: 10.1016/j.scitotenv.2015.09.112

Hankin S.M., Peters S.A.K., Poland C.A., Foss Hansen S., Holmqvist J., Ross B.L., Varet J. and Aitken R.J. 2011. Specific Advice on Fulfilling Information Requirements for Nanomaterials under REACH (RIP-oN 2) Final Project Report

Hansen, S. F., Larsen, B. H., Olsen, S. I., Baun, A. 2007. Categorization framework to aid Hazard Identification of Nanomaterials. Nanotoxicology 1, 243-250.

Hansen, S.F., Maynard, A., Baun, A., Tickner, J.A., Bowman, D.M. 2013. Nanotechnology — early lessons from early warnings. In: Gee et al. (Eds.). Late lessons from early warnings: science, precaution, innovation. European Environment Agency, Copenhagen, Denmark. Available at:

\section{http://www.eea.europa.eu/publications/late-lessons-2}

Hartmann, N.B., Skjolding, L.M., Hansen, S.F., Kjølholt, J., Gottschalck, F., Baun, A. 2014. Environmental fate and behaviour of nanomaterials New knowledge on important transformation processes. Environmental Project No. 1594, 2014. Copenhagen: The Danish Environmental Protection Agency

HCN 1989. Assessing the risk of toxic chemicals for ecosystems. Report 1988/28E. Health Council of the Netherlands. The Hague, The Netherlands

Heinlaan, M., Ivask, A., Blinova, I., Dubourguier, H., Kahru, A. 2008. Toxicity of nanosized and bulk ZnO, $\mathrm{CuO}$ and $\mathrm{TiO} 2$ to bacteria Vibrio. fischeri and crustaceans Daphnia magna and Thamnocephalus platyurus. Chemosphere 71, 1308-1316

Holmes, J., Clark, R. 2008. Enhancing the use of science in environmental policymaking and regulation. Environ Sci Policy. 11, 702-711

Hund-Rinke, K., Simon, M. 2006. Ecotoxic effect of photocatalytic active nanoparticles TiO2 on algae and daphnids. Environ Sci Pollut R 13(4), 225-232.

JRC 2014. Towards a review of the EC Recommendation for a definition of the term "nanomaterial" Joint Research Centre, Ispra, Italy 
This is a post-print version of Syberg, K., \& Hansen, S. F. (2016). Environmental risk assessment of chemicals and nanomaterials - The best foundation for regulatory decision-making? Science of the Total Environment, 541, 784-794. The printed version of the paper is available at: DOI: 10.1016/j.scitotenv.2015.09.112 Kahl, M.D., Makynen, E.A., Kosian, P.A., Ankley, G.T. 1997. Toxicity of 4-Nonylphenol in a Life-Cycle Test with the Midge Chironomus tentans. Ecotoxicol. Environ. Saf. 38(2), 155-160

Kavlock, R.J., Daston, G.P., DeRosa, C., Fenner-Crisp, P., Gray, L.E., Kaattari, S., Lucier, G., Luster, M., Mac, M.J., Maczka, C., Miller, R., Moore, J., Rolland, R., Scott, G., Sheehan, D.M., Sinks, T., Tilson, H.A. 1996. Research needs for the risk assessment of health and environmental effects of endocrine disrupters: A report of the U.S. EPA-sponsored workshop. Environmental Health Perspectives, 104 (SUPPL. 4), pp. 715740.

Khan,F.R., Schmuecking,K., Krishnadasan, S.H., Berhanu, D., Smith, B.D., deMello, J.C., Rainbow, P.S., Luoma, S.N., Valsami-Jones, E. 2013. Dietary bioavailability of cadmium presented to the gastropod Peringia ulvae as quantum dots and in ionic form. Environ. Toxicol. Chem. 32(11), 2621-2629

Klimisch, H.J., Andreae, M., Tillmann, U. 1997. A Systematic Approach for Evaluating the Quality of Experimental Toxicological and Ecotoxicological Data. Regul. Toxicol. Pharm. 25(1), 1-5

Kooijman, S.A.L.M. 1985. Toxicity at population level. In J. Cairns, editor, Multispecies toxicity testing. Pergamon Press, New York

Kooijman, S.A.L.M. 1987. A safety factor for LC50 values allowing for differences in sensitivity among species. Water Res. 21, 269-276

Kortenkamp, A., Backhaus, T., Faust, M. 2009. State of the Art Report on Mixture Toxicity. Final Report. European Commission, Bruxelles, Belgium

Kühnel, D., Busch, W., Meißner, T., Springer, A., Potthoff, A., Richter, V., Gelinsky, M., Scholz, S., Schirmer, K. 2009. Agglomeration of tungsten carbide nanoparticles in exposure medium does not prevent uptake and toxicity toward a rainbow trout gill cell line. Aquat Toxicol, 93(2-3), 91-99 
This is a post-print version of Syberg, K., \& Hansen, S. F. (2016). Environmental risk assessment of chemicals and nanomaterials - The best foundation for regulatory decision-making? Science of the Total Environment, 541, 784-794. The printed version of the paper is available at: DOI: 10.1016/j.scitotenv.2015.09.112

1 Kwak, H., Bae, M., Lee, M., Lee, Y., Lee, B., Kang, K., Chae, C., Sung, H., Shin, J., Kim, J., Mar, W., Sheen, Y., Cho, M. 2001. Effects of nonylphenol, bisphenol a, and their mixture on the viviparous swordtail fish (Xiphophorus helleri). Environ. Toxicol. Chem. 20(4), 1552-8618

Lavoie, E.T., Heine, L.G., Holder, H., Rossi, M.S., Lee, R.E., Connor, E.A., Vrabel, M.A., DiFiore, D.M., Davies, C.L. 2010. Chemical Alternatives Assessment: Enabling Substitution to Safer Chemicals. Environ. Sci. Technol. 44(24), 9244-9249

Lee H.J., Chattopadhyay S., Gong E.Y., Ahn R.S., Lee K. 2003. Antiandrogenic effects of bisphenol A and nonylphenol on the function of androgen receptor. Toxicol Sci. 75(1), 40-46

Levis, M.A. 1992. The effects of mixtures and other environmental modifying factors on the toxicities of surfactants to fresh-water and marine life. Water Res., 26(8), 1013-1023

Löfsted, R.E. 2011. Risk versus Hazard - How to Regulate in the 21st Century. Eur J Risk Regul. 2, 149-168

Lovern, S. B., Strickler, J. R., Klaper, R. 2007. Behavioral and Physiological Changes in Daphnia magna when Exposed to Nanoparticle Suspensions (Titanium Dioxide, Nano-C60, and C60HxC70Hx). Environ Sci Technol 41(12), 4465-4470.

Myers J.P., vom Saal F.S., Akingbemi B.T., Arizono K., Belcher S., Colborn T., Chahoud I., Crain D.A. , Farabollini F., Guilleffe L.J., Hassold T., Ho S.M., Hunt P.A., Iguchi T., Jobling S., Kanno J., Laufer H., Marcus M., Mclachlan J.A., Nadal A., Oehlmann J., Olea N., Palanza P., Parmigiani S., Rubin B.S., Schoenfelder G., Sonnenschein C., Soto A.M., Taisness C.E., Taylor J.A., Vandenberg L.N., Vandenbergh J.G., Vogel S., Watson C.S., Welshons W.V., Zoeller R.T. 2009. Why public health agencies cannot depend upon ‘Good Laboratory Practices’ as a criterion for selecting data: the case of bisphenol-A. Environ. Health Perspect. 117(3), 309-315.

Nielsen E., Østergaard G., Thorup I., Ladefoged O., Jelnes O., Jelnes J.E. 2000.Toxicological evaluation and limit values for nonylphenol ethoxylates, ticresyl, phosphates and benzoic acid. Environmental Project (Miljøprojekt), No. 512. The Danish Environmental Protection Agency, Denmark. 
This is a post-print version of Syberg, K., \& Hansen, S. F. (2016). Environmental risk assessment of chemicals and nanomaterials - The best foundation for regulatory decision-making? Science of the Total Environment, 541, 784-794. The printed version of the paper is available at: DOI: 10.1016/j.scitotenv.2015.09.112 Government Action to Address Risk Has Not. House Committee on Science. USA

Nordan, M.M., Holman, M.W., Bünger, M. 2006. Nanotech Commercialization Has Advanced, but

NRC 1983. Risk assessment in the federal government. Managing the process. National Research Council.

National Academy Press, Washington, DC.

Oberdörster G, Oberdörster E, Oberdörster J. 2007. Concepts of Nanoparticle Dose Metric and Response Metric. Environ Health Perspect 115(6), A 290.

OECD 1992. Report of the OECD Workshop on the Extrapolation of Laboratory Aquatic Toxicity Data to the Real Environment. OECD Environment Monographs No. 59, Organisation for Economic Co-operation and Development, Paris.

Okamoto,Y., Hayashi T., Matsunami S., Ueda K., Toda C., Kawanishi S., Kojima N. 2006. Formation of DNA Damaging Nonylphenol Product from Light-lrradiated Nonylphenol. Journal of health science 52(1), 91-95

Premises for Risk Management (1989) Risk limits in the context of environmental policy. Directorate-

General for Environmental Protection at the Ministry of Housing, Physical Planning and Environment.

Second Chamber of the State General, 1988-89 session, 21137, no.s 1-2. The Hague. Available at: http://www.coenrady.com/downloads/handig/pdf017.pdf

Rajapakse N, Silva E, Scholze M, Kortenkamp A 2004. Deviation from additivity with estrogenic mixtures containing 4-nonylphenol and 4-tert-octylphenol detected in the E-SCREEN assay. Environ Sci Technol 38 : 6343-6352.

RCEP 2008. Twenty-seventh Report Novel Materials in the Environment: The case of nanotechnology Royal Commission on Environmental Pollution. The Stationery Office, Norwich, UK

SCENIHR. 2007. Scientific Committee for Emerging and Newly-Identified Health Risks (SCENIHR) The appropriateness of the risk assessment methodology in accordance with the Technical Guidance Documents 
This is a post-print version of Syberg, K., \& Hansen, S. F. (2016). Environmental risk assessment of chemicals and nanomaterials - The best foundation for regulatory decision-making? Science of the Total Environment, 541, 784-794. The printed version of the paper is available at: DOI: 10.1016/j.scitotenv.2015.09.112

for new and existing substances for assessing the risks of nanomaterials. European Commission, Bruxelles,

\section{Belgium}

Schmidt, K. 2007. Nanofrontiers Visions for the future of Nanotechnology. PEN 6. Washington, D.C.:

Project for Emerging Nanotechnologies, Woodrow Wilson International Center for Scholars.

Scientific Committees 2013. Addressing the New Challenges for Risk Assessment. Scientific Committee on Health and Environmental Risks SCHER, Scientific Committee on Emerging and Newly Identified Health

Risks SCENIHR, Scientific Committee on Consumer Safety SCCS, European Commission, Bruxelles, Belgium

Slooff, W., Van Oers, J.A.M., De Zwart, D. 1986. Margins of uncertainty in ecotoxicological hazard assessment. Environ. Toxicol. Chem. 5(9), 1552-8618

Slovic, P. 1999. Trust, Emotion, Sex, Politics, and Science: Surveying the Risk-Assessment Battlefield. Risk analysis, 19(4), 689-701.

Soares, A., Guieysse, B., Jefferson, B., Cartmell, E., Lester, J.N., 2008. Nonylphenol in the environment: a critical review on occurrence, fate, toxicity and treatment in wastewaters. Environ. Int. 34, 1033-1049

Stephan, C. E., Mount, D. I., Hansen, D. J., Gentile, J. H., Chapman, G. A., Brungs, W. A. 1985. Guidelines for deriving numerical national water quality criteria for the protection of aquatic organisms and their uses. US Environmental Protection Agency. PB85-227049, Springfield, VA

Syberg, K. Jensen, T.S., Cedergreen, N., Rank, J. 2009. On the use of mixture toxicity assessment in REACH and the water framework directive: a review. Hum Ecol Risk Assess. 15(6), 1257-1272

Templeton, R. C., Ferguson, P. L., Washburn, K. M., Scrivens, W. A., Chandler, G. T. 2006. Life-cycle effects of single-walled carbon nanotubes (swnts) on an estuarine meiobenthic copepod. Environ. Sci.

Technol. 40 (23), 7387-7393 
This is a post-print version of Syberg, K., \& Hansen, S. F. (2016). Environmental risk assessment of chemicals and nanomaterials - The best foundation for regulatory decision-making? Science of the Total Environment, 541, 784-794. The printed version of the paper is available at: DOI: 10.1016/j.scitotenv.2015.09.112

US EPA 1984. Risk Assessment and Management: Framework for Decision Making. EPA 600/9-85-002. U. US EPA 1992. Framework for ecological risk assessment. EPA/630/R-92/001. U.S. Environmental Protection Agency, Washington, DC US EPA 1998. Guidelines for Ecological Risk Assessment. Federal Register 63(93):26846-26924. U.S. Environmental Protection Agency, Washington, DC U.S. EPA 2007. Nanotechnology White Paper. EPA 100/B-07/001. U.S. Environmental Protection Agency, Washington, DC Van Hoecke K., De Schamphelaere K. A., Van der Meeren P., Lucas S., Janssen C. R., 2008. Ecotoxicity of silica nanoparticles to the green alga Pseudokirchneriella subcapitata: importance of surface area. Environ. Toxicol. Chem. 27(9), 1948-1957. van Leeuwen, C.J., Vermeire, T.G. (Eds.) 1995. Risk Assessment of Chemicals: An Introduction. Springer Netherlands. Van Straalen, N.M. (1987). Stofgehalten in de bodem- (geen) effecten op bodemdieren. In Symposium Bodemkwaliteit, Ede. Rapport VTCB M86/44, Leidschendam, pp. 75-84.

Van Straalen, N. and Van Leeuwen, C. 2002. European history of species sensitivity distributions. In: Species Sensitivity Distributions in Ecotoxicology (Eds. L. Posthuma, G. W. Suter II \& T. P. Traas). Lewis Publishers, Boca Raton. pp.19-34 WHO 2013. Nanotechnology and human health: Scientific evidence and risk governance. Report of the WHO expert meeting 10-11 December 2012, Bonn, Germany. Working Party Risk Management for Ecosystems 1987. Integrated Criteria Documents: Toxicological Data 